\title{
Agricultura, pecuária, legislação e meio ambiente: ruralidades contemporâneas em Florianópolis
}

\author{
Agriculture, legislation and environment: contemporary ruralities in Florianopolis
}

La agricultura, la legislación y el medio ambiente: ruralidades contemporáneos en Florianópolis

Giovana Callado*

\section{Resumo}

O município de Florianópolis tem a maior parte de seu território estabelecida em uma ilha, dos $436,5 \mathrm{~km}^{2}$, apenas $12,1 \mathrm{~km}^{2}$ formam a parte continental. A configuração territorial insular traz em si limites ao crescimento urbano. Pela legislação vigente, $42 \%$ do território ilhéu enquadram-se como área de preservação permanente. A ilha foi, até meados do século $\mathrm{XX}$, espaço de atividade agrícola e pastoril, e foi profundamente transformada a partir da década de 1970, devido ao processo de expansão urbana em direção aos antigos núcleos de atividade pesqueira e agrícola. A abertura de vias de acesso, acompanhada de um projeto político de transformação do município capital, operou significativas transformações nos modos de vida das populações residentes nos antigos núcleos localizados no entorno da ilha. O processo de expansão urbana, acompanhado pelo declínio das atividades agrícolas e pastoris, não levou à sua eliminação, mas, sim, transformou suas práticas e produziu novas relações entre homem e meio ambiente. A partir da década de 1980, um novo plano diretor definiu as áreas de preservação, criou parâmetros para os usos da terra e para a expansão urbana. Este artigo tem por objetivo analisar as transformações nas práticas de agricultura e pecuária criadas em Florianópolis a partir dos processos de urbanização e da elaboração da legislação ambiental que incide sobre os usos da terra. Esses são os elementos norteadores para a emergência de novas ruralidades, ruralidades contemporâneas.

Palavras-chave: Ruralidade. Agricultura. Meio ambiente.

" Mestre em História pela Universidade Federal de Santa Catarina. Doutoranda no Programa de Pós-Graduação em História da Universidade Federal de Santa Catarina. E-mail: gicallado@yahoo.com.br

Recebido em 27/09/2015 - Aprovado em 22/01/2016 http://dx.doi.org/10.5335/hdtv.16n.1.6267 


\section{Introdução}

A Ilha de Santa Catarina está localizada na Região Sul do Brasil, é a capital do estado de Santa Catarina e conta com uma área de $424,4 \mathrm{~km}^{2}$, separada do continente pelas Bahias Norte e Sul. O município de Florianópolis tem seus limites geográficos configurados da seguinte forma: dividido por duas porções de terra, uma refere-se à Ilha de Santa Catarina, com área de 436,5 $\mathrm{km}^{2}$, de forma alongada no sentido norte e sul, e outra porção localizada na área continental, com área de $12,1 \mathrm{~km}^{2}$, conhecida como continente, limitando-se a oeste com o município de São José (LIMA, 2007, p. 214). A proximidade com o continente permite considerá-la uma ilha continental.

A Ilha de Santa Catarina tem hoje $42 \%$ do seu território como área de preservação permanente (APP). De qualquer modo, as diferentes formas de ocupação desse território, seja pela agricultura, nos séculos XVIII, XIX e XX, seja pela urbanização, decorrente da expansão turística e imobiliária, promoveram transformações sociais, ambientais, econômicas e culturais muito importantes. Essas mudanças, por um lado, ameaçam cotidianamente os ecossistemas da ilha, acarretando alterações ambientais, por vezes, irreversíveis, e, por outro, tem suscitado alterações no modo como os sujeitos lidam com o ambiente. A legislação por si só não é capaz de evitar a ocupação das áreas preservadas, mas é o elemento norteador de condutas. Antigos moradores de áreas rurais, que outrora derrubaram a mata para o plantio, hoje reinventam sua relação com a terra, com os animais e com o ambiente.
A ocupação da Ilha de Santa Catarina, durante os séculos XVIII e XIX, promoveu alterações ambientais por distintas razões, houve desmatamento para utilizar a madeira na construção naval, civil e de móveis, para a exportação e também para a retirada da lenha para uso doméstico, para engenhos, curtumes, olarias, navios e para a transformação do solo para a agricultura (REIS, 2012, p. 88-89). “Os dois ecossistemas insulares mais impactados pela ocupação colonial foram a mata Atlântica e as restingas, a partir da necessidade de solo para a agricultura" (REIS, 2010, p. 51).

Desde a década de 1980, registra-se na região metropolitana de Florianópolis um declínio das atividades da agricultura e da pecuária, o que propiciou a regeneração de parte da vegetação extraída ao longo do tempo. As áreas do território ilhéu ocupadas por diversos cultivos até a década de 1970 encontram-se em diferentes estágios de regeneração. Essas áreas, em retrospecto, passam por transformações significativas desde o século XVIII. Susana Cesco afirma que, com relação à derrubada de mata e corte de árvores, foram definidos pela legislação portuguesa, ainda no século XVIII, os preceitos legais relativos a essa questão. Essa primeira disposição legal determinava que:

[...] as madeiras reservadas ou, posteriormente, designadas como madeiras de lei - não mais poderiam ser usadas pela população local para suas caieiras, seus engenhos (CESCO, 2011, p. 197).

A criação dos preceitos legislativos não impediu o processo de transformação ambiental decorrente da derrubada da mata. Um elemento que teve influência decisiva 
sobre a transformação do meio ambiente foi a construção dos engenhos. Os engenhos estiveram espalhados por diferentes regiões da ilha e, no final do século XVIII, havia mais de quinhentos em funcionamento, com destaque para os engenhos de farinha de mandioca. A implantação de engenhos produtores de farinha de mandioca trouxe transformações ambientais significativas para a então cidade de Nossa Senhora do Desterro e suas freguesias. Os engenhos não figuram sozinhos no processo de alteração ambiental gerado na ilha em função da implantação das unidades produtivas de farinha de mandioca. A própria agricultura familiar implementada na área implicou significativas mudanças no ambiente. A agricultura necessita de espaço, isso significa território limpo, consequentemente, o desmatamento de uma área (FERREIRA, 2010, p. 31). Uma antiga freguesia da ilha, que teve sua ocupação assentada na agricultura familiar, foi a Freguesia da Lagoa da Conceição.

A Lagoa da Conceição é hoje um dos cartões postais da cidade de Florianópolis, procurada pelos turistas em busca de seus restaurantes à beira da lagoa, dos esportes náuticos e das rendas produzidas artesanalmente pelas rendeiras do lugar. Esse é um dos pontos da cidade transformados nos aspectos ambiental, econômico e sociocultural a partir dos usos da terra elaborados por homens e mulheres por meio da agricultura. A agricultura praticada na Freguesia da Lagoa, no final do século XIX, era caracterizada como de dinâmica familiar, na qual pequenos lavradores praticavam a subsistência, trocavam ou vendiam o excedente produzido. Essa prática agrícola é feita após a derrubada-queimada, conhecida como coivara. Muitas áreas foram desmatadas nesse sistema, no qual se utilizava a terra por um determinado período até que, uma vez diminuída a fertilidade do solo, migrava-se para novas áreas.

Além disso, novas ameaças pairam sobre o meio ambiente da ilha. Atualmente, a principal ameaça à mata Atlântica na ilha é a expansão urbana, uma vez que as derrubadas e queimadas para a abertura de pequenas roças são pouco expressivas Se comparadas à crescente expansão urbana, cada vez mais marcante em bairros periféricos, na forma de loteamentos e ocupações, legais e ilegais (GUERINI, 2000, p. 61). O loteamento do solo para condomínios ou grandes empreendimentos imobiliários, ao contrário das áreas em regeneração devido ao abandono de práticas da agricultura e pecuária, são irreversíveis.

Dessa forma, a relação existente, nas quatro últimas décadas, entre urbanização e transformação dos usos da terra, com novas e mais impactantes consequências ao meio ambiente, fica evidente na Ilha de Santa Catarina. Na Ilha de Florianópolis do tempo presente, novas práticas, reelaboradas por muitos daqueles que tiveram suas famílias ligadas ao trabalho agrícola, ressignificam suas formas de lidar com a terra, muitas vezes, não mais tirando dela sua subsistência, criando novos sentidos para os vínculos com o solo e promovendo novas relações entre o homem e o meio ambiente.

Na Florianópolis dos últimos 25 anos, a existência de uma legislação definindo as áreas de preservação permanente e as áreas de preservação limitada (APLs) serviu para 
que os moradores dessas áreas de preservação construíssem novas formas de interação com o meio que os circunda.

Essa legislação foi estruturada no Plano Diretor dos Balneários e Interior da Ilha, que, pela primeira vez, teve como base o interior do território insular como um todo, reconhecendo as transformações acarretadas pelo turismo e pelo crescimento urbano. Os primeiros planos, aprovados nas décadas de 1950 e 1970, tiveram como prioridade as relações entre o centro urbano e a área continental. Esse plano diretor, datado de 1985, buscou diretrizes para ordenar o crescimento do interior insular, demarcou as áreas de proteção ambiental e estabeleceu limites de ocupação. Com vistas a conter o crescimento desordenado e propiciar a continuidade das atividades chamadas tradicionais (agricultura e pesca), foram criados zoneamentos específicos. Assim foram criadas as áreas de exploração rural, cujo objetivo era conter o crescimento urbano e turístico desordenado e propiciar a continuidade das atividades tradicionais.

A fragilidade desse processo ficou evidente quando, nos anos subsequentes à criação do plano diretor, muitas áreas rurais foram transformadas em áreas de expansão urbana, por meio de alterações legais dos perímetros urbanos ou de ocupações clandestinas. Tendo por base esse plano é que são apontados como problemas graves da ilha os impactos ambientais decorrentes das transformações urbanas e turísticas. Então, a prioridade de demarcação de áreas de preservação ambiental gerou medidas nesse sentido (REIS, 2012). A respeito disso, Reis afirma:
Tais medidas geraram as Áreas de Preservação Permanente (APP) e as Áreas de Preservação de Uso Limitado (APL), demarcadas a partir da legislação (a nível federal, o Código Florestal e o Código das Águas, a que se juntam numerosas leis de proteção ao meio ambiente), além, das já protegidas como Parques ou Reservas (Parque da Lagoa do Peri, estação Florestal do Rio Vermelho, pequena Porção do Parque da Serra do Tabuleiro, dunas da Joaquina) [...] a aplicação de tais critérios sobre a Ilha fez com que $42 \%$ do seu território ficasse enquadrado como APP (189,42 km), e 17\% como APL $(74,60 \mathrm{~km})(2012$, p. 181, 207).

A existência da legislação não impediu que muitas dessas áreas continuassem sendo ocupadas. A ocupação da urbanização e do turismo ocorre em áreas que foram ocupadas anteriormente com atividade agrícola e de pecuária e que, neste momento, têm vegetação em diferentes estágios de conservação.

Portanto, as questões que se destacam são: Como são construídas as relações entre as populações (que tiveram suas vidas ligadas à agricultura e à pecuária e, ainda hoje, mantêm terrenos de produção agrícola e pecuária, em terrenos agora enquadrados na legislação como APP ou APL) e as novas determinações legais? Como essas medidas e sua fiscalização tornam-se artifícios de reelaboração das relações homem-ambiente?

\section{Agricultura, legislação e as novas ruralidades}

As mudanças na legislação aliadas aos discursos em prol da preservação do meio ambiente são os elementos a partir dos quais homens e mulheres vão transformar suas 
práticas com relação à terra e ao meio circundante. Foi possível perceber, nas narrativas dos entrevistados desta pesquisa, que existe o reconhecimento das mudanças na legislação e, também, o entendimento quanto às alterações que já são visíveis diante da diminuição dos usos da terra para a agricultura.

Hermínio Euclides dos Santos, ${ }^{1}$ o Nem, morador do Distrito do Rio Vermelho, durante entrevista realizada para este trabalho, apontava para o morro que fica em frente à sua residência e enfatizava: "[...] agora tem mais vegetação que antigamente". Nas suas palavras:

[...] porque hoje a população cresceu, mas hoje tem mais vegetação que antigamente, porque todo mundo tirava, não existia gás, então tinha que cortar as árvores todas para a lenha, nós pegava umas mata aí e tirava trinta carrada de lenha do morro.

A explicação do, hoje, comerciante aposentado para a retirada da lenha tinha relação com a sobrevivência, ele explicou que a vida da família do pai agricultor era cultivar a terra e trazer lenha para a produção da farinha: "[...] fazia a roçada aí nos morros que era pra ter lenha pra poder fazer farinha".

Esse reconhecimento da transformação do meio também ficou evidente na fala de Claudinei Bairrão, ${ }^{2}$ o Nei, um forneador de farinha morador da região norte da Ilha de Santa Catarina:

[...] na época que eu me criei, era pequeno, o morro era limpo, tu via toda pedra, era tudo derrubado, queimado, hoje de vinte anos pra cá tu não vê mais o fogo no morro, hoje tá tudo [...] não pode [...] se alguém já reclama da fumaça [...] pra ti plantar tu é obrigado a roçar o mato.
O reconhecimento da proibição da queimada esteve presente em diferentes narrativas, o que não impediu os agricultores de reservarem pedaços dos seus terrenos para o cultivo agrícola. A proibição das queimadas está definida na Lei $\mathrm{n}^{\circ} 14.675$, de 13 de abril de 2009, que institui o Código Estadual do Meio Ambiente, que em seu artigo 253 determina:

É proibido promover queimadas, inclusive para limpeza de áreas destinadas à formação de reservatórios, exceto quando autorizado pelo órgão competente, que exigirá - comprovação de que constitui o único modo viável de manejo da propriedade, ante às suas peculiaridades, assim reconhecido por responsável técnico; II - adoção das medidas preventivas contra incêndios e queima de áreas protegidas; e III - adoção das demais medidas previstas contidas em instrução normativa da FATMA (SANTA CATARINA, 2009).

Essa mesma região do norte da ilha, hoje parte de um balneário conhecido internacionalmente por suas mansões e por apresentar um dos metros quadrados mais caros do Brasil, o bairro de Jurerê abriga um engenho de farinha de mandioca e quintais com cultivos agrícolas. Em terreno situado no Canto do Lamim, parte do referido bairro, o engenho em questão está no terreno que abriga a Associação Folclórica do Boi de Mamão de Jurerê, onde Nei, forneador, costuma participar do fabrico da farinha. Nessa mesma área, em um pequeno espaço lateral, fica o roçado reservado para o cultivo da mandioca. Ainda que o forneador Nei afirme que agora "não pode mais" fazer queimadas, um pedaço do solo exibe a plantação da mandioca. O terreno em questão é 
de propriedade de Sérgio Antônio de Souza ${ }^{3}$ (Marreba), presidente da associação.

Sérgio deixou claro que, quando vai produzir farinha, a mandioca plantada no terreno ao lado não supre as necessidades da produção. Ele afirmou buscar a raiz nos municípios vizinhos a Florianópolis: "essa mandioca tá vindo lá de Laranjal, próximo a Paulo Lopes", relatou Sérgio. De qualquer modo, novas relações vão sendo construídas, pois os morros considerados áreas de proteção pela legislação vigente são parte de propriedades com uma parte plana, já bastante alterada, que hoje, normalmente, são as ilhas de cultivo de agricultores aposentados.

Reelaborar as relações com o meio ambiente tornou-se uma necessidade a partir do processo de urbanização e da legislação que acompanhou esse processo. $\mathrm{O}$ conhecimento das espécies, dos diferentes tipos de cultivos, já fazia parte do acervo de práticas utilizadas nos usos com a terra. Agora, novos saberes são divulgados e impostos pelos poderes constituídos em prol da defesa do meio ambiente. $\mathrm{O}$ que antes era corriqueiro tornou-se, então, proibitivo. As queimadas eram corriqueiras segundo apontam estudos sobre a agricultura na ilha, fato que foi corroborado nas entrevistas realizadas. A legislação ambiental proibiu as queimadas.

Além da proibição às queimadas, a legislação ambiental trouxe no seu arcabouço de preceitos espécies que passaram a ter seu corte regulamentado por lei, por serem classificadas na categoria das variedades ameaçadas. Algumas dessas espécies, como o palmito, incluídas na lista de espécies ameaçadas de extinção, eram bastante comuns na Ilha de Santa Catarina, e muitas famílias tiveram de reelaborar suas práticas de corte e consumo.

O Ministério do Meio Ambiente, por meio da Instrução Normativa $n^{0} 6$, de 23 de setembro de 2008, assim define as espécies ameaçadas de extinção e os cuidados para com elas:

Secretaria de Biodiversidade e Florestas, do Ministério do Meio Ambiente, e ao Instituto Brasileiro do Meio Ambiente e dos Recursos Naturais Renováveis-IBAMA, resolve: Art. $1^{\circ}$ Reconhecer como espécies da flora brasileira ameaçadas de extinção aquelas constantes do Anexo I a esta Instrução Normativa. Art. $2^{\circ}$ Reconhecer como espécies da flora brasileira com deficiência de dados aquelas constantes do Anexo II a esta Instrução Normativa. Art. $3^{\circ}$ Entende-se por espécies: I - ameaçadas de extinção: aquelas com alto risco de desaparecimento na natureza em futuro próximo, assim reconhecidas pelo Ministério do Meio Ambiente, com base em documentação científica disponível; II - com deficiência de dados: aquelas cujas informações (distribuição geográfica, ameaças/ impactos e usos, entre outras) são ainda deficientes, não permitindo enquadra-las com segurança na condição de ameaçadas; Art. $4^{\circ}$ As espécies consideradas ameaçadas de extinção constantes do Anexo I a esta Instrução Normativa estão sujeitas às restrições previstas na legislação em vigor e sua coleta, para quaisquer fins, será efetuada apenas mediante autorização do órgão ambiental competente (BRASIL, 2008).

A palmeira Juçara (Euterpe edulis), presente nas regiões de mata Atlântica, incluindo a Ilha de Santa Catarina, aparece no Anexo I da referida lei como espécie ameaçada de extinção.

O senhor Divo da Silva, ${ }^{4}$ agricultor, mantém no Canto do Moreira, região de 
Ratones (norte da ilha) um terreno que está dentro da APP, e conhece as possibilidades de uso da terra e da vegetação no terreno de sua propriedade. Sobre retirar palmito para o consumo, ele afirma:

Se nós cortar, alguém denunciar, ele vem aqui dá uma carcada em nós. Se nós quiser comer um ou dois, mesmo que plantou palmito, o lbama é assim: você chega lá pega uma ordem, eu quero plantar 1.000 pés de palmito. Eles vê a área, quando tiver bom de colher, cortar, eles vão cá. $20 \%$ tem que deixar [...] aí bota um selo naquele que vai ficar, de 100 fica 20 [...] só esse que plantemos, do morro não pode mexer. Tem que plantar com autorização dele [...] não pode tirar lenha, não pode tirar mais nada.

A legislação cria uma série de novas regras para lidar com a terra e com as diferentes espécies nela encontradas. O senhor Divo conhece os riscos envolvidos em descumprir tais premissas, ele afirmou: "se cortar e alguém denunciar vai preso [...] não tem fiança". De qualquer forma, pequenas estratégias também são criadas para que a família possa utilizar para o consumo próprio alimentos que outrora eram corriqueiros na sua mesa. Assim, esse agricultor confidenciou: "se nós quiser comer um, nós corta".

As transformações urbanas e a nova legislação implicaram mudanças nas relações entre as famílias e o meio ambiente, entre as famílias e as práticas agrícolas por eles desenvolvidas. Portanto, se as restrições das áreas de cultivo assim como das espécies cultivadas acarretaram mudanças, elas não levaram ao desaparecimento das práticas de agricultura na ilha, que foram, e ainda estão sendo, ressignificadas pelas famílias que têm com a terra uma relação não mais apenas de sobrevivência, mas também de construção simbólica de pertencimento. As práticas de tantos agricultores na Ilha de Santa Catarina, que não têm mais na agricultura sua única fonte de renda, encontram nos usos agrícolas da terra sentidos para um rural transformado, do qual eles sentem fazer parte.

O agricultor aposentado Divo da Silva e sua esposa, Doralice Genair da Silva, ${ }^{5}$ mantêm, atualmente, uma diversificada produção agrícola no terreno que está enquadrado na legislação como APP. Essa produção agrícola diversificada inclui milho, feijão, mandioca, melancia e abóbora, produtos que atendem ao consumo da família, composta por sete filhos, e ainda é distribuída aos amigos e, por fim, é vendida para os moradores locais. Dona Genair faz questão de destacar o destino dos produtos colhidos no seu quintal:

[...] cenoura, abóbora, tem tudo quanto é coisa aí, salsinha, cebolinha verde, aí a gente consome e o que sobra dá pra família e pros amigos, dá tudo, ele não vende, negócio assim de vender, assim só que ele vende quando sobra o alho, cebola e feijão, é onde ele vende, porque as outras coisas ele dá tudo pra família e pros amigos dele ao redor da porta [...] aí tem feijão, milho, não milho é pras galinhas [...] aí ele vende é o feijão, quando sobra, e o alho e a cebola e a mandioca [...] ele vai na venda, um encomenda 80 quilos de aipim, outro encomenda $70[\ldots]$.

A explicação da senhora Genair para o destino da sua plantação, a distribuição aos familiares e amigos "ao redor da porta", permite perceber outra questão importante do 
debate sobre o rural na contemporaneidade, a saber: a ampliação da definição do que é agricultor. Há um deslocamento do conteúdo meramente econômico da agricultura para a questão da identidade social.

O que é relevante aqui é:

[...] a contribuição da agricultura na manutenção e no fortalecimento do tecido social ao possibilitar [...] a continuidade das trocas e das práticas de sociabilidade que dão sentido à vida de um determinado grupo social (CARNEIRO; TEIXEIRA, 2012, p. 92).

Essa prática de produção voltada para a família é importante também por exercer a função primordial de garantia das necessidades de autoconsumo.

Essas práticas de cultivo agrícola estão presentes em meio aos espaços que na Florianópolis contemporânea perderam a denominação de áreas rurais. Cabe destacar que no Plano Diretor Participativo, aprovado em janeiro de 2014, para o município de Florianópolis, foram extintas as denominações de áreas antes intituladas rurais. Aqui, o rural e o urbano não são pensados como espacialidades físicas, mas, sim, como universos territoriais dinâmicos e híbridos. João Rua, em interessante reflexão sobre os debates que hoje tratam dos processos de urbanização, defende que as transformações vivenciadas a partir dessa passagem promovem algo novo, um espaço híbrido.

Logo o espaço híbrido que resulta dessas interações, não é um urbano ruralizado nem um rural urbanizado. É algo novo, ainda por definir e que desafia pesquisadores, tanto dos países da OCDE [...] como em países como o Brasil (RUA, 2006, p. 95).
Dessa forma, em meio às áreas urbanas do novo plano diretor, muitos proprietários mantêm seus cultivos, criam animais, possuem carros de boi e engenho de farinha de mandioca. Essas práticas, cada vez mais, tornam esses territórios espaços híbridos. Manoel Candido dos Anjos, ${ }^{6} 63$ anos, agricultor aposentado, morador do Distrito do Rio Vermelho, por exemplo, é proprietário de engenho de farinha, de carro de bois e mantém uma plantação de mandioca. Sua narrativa entrelaça fragmentos de suas histórias passadas com suas práticas cotidianas do presente, o que comprova que o rural não desapareceu com esse processo, em especial aquele trecho da ilha, o Distrito do Rio Vermelho:

[...] meu pai também era lavrador, a gente foi criado com isso aí, naquele tempo a gente plantava mandioca, milho, depois aí se acabou [...] aí eu também trabalhava fora, trabalhei na prefeitura também, trabalhei 38 anos na prefeitura, já tocava roça [...] eu chegava do serviço vinha pra roça, era todo dia, não podia parar, agora eu tô aposentado. Aí a gente faz serviço em casa, capina, roça, essas coisas toda aí [...].

Nas narrativas desse senhor, é possível descortinar experiências e percepções da cidade em que estão presentes fragmentos de uma vida rural, que sobrevive nas fissuras de um processo que deliberadamente não é homogêneo. $\mathrm{O}$ interessante é perceber que elementos desse mundo rural continuam a existir em meio à cidade, articulados com elementos do presente, uma demonstração de que as práticas de vida de um mundo conhecido como rural, e que se acredita fadado ao desaparecimento, insiste em sobreviver. 
As entrevistas realizadas com pessoas como o senhor Manoel dos Anjos, morador das áreas do interior de Florianópolis, mostraram que relações e experiências tidas como rurais manifestam-se nos espaços hoje considerados urbanos. Mesmo estando em meio a um ambiente completamente alterado e não mais tendo as atividades da pesca e da agricultura como elementos centrais de sobrevivência desses moradores, práticas de um mundo rural são constantemente reelaboradas e ressignificadas nos espaços da urbe em questão.

\section{Da criação de gado ao engenho elétrico}

Outra atividade que mantém vínculos com a terra na Ilha de Santa Catarina é a pecuária. Segundo dados da Companhia Integrada de Desenvolvimento Agrícola de Santa Catarina, na Ilha de Santa Catarina, atualmente, estão registradas 3.100 cabeças de bovinos, de 324 criadores, 1.116 cabeças de equinos, de 185 criadores, 470 cabeças de caprinos, de 29 criadores, e 366 cabeças de ovinos, de 23 criadores. Os bovinos predominantes são zebu, holandês vermelho e preto e branco, jersey, nelore e gir leiteiro. Os rebanhos estão localizados na região norte da ilha, em Rio Vermelho, Sítio do Capivari/Ingleses, Cachoeira do Bom Jesus, Canasvieiras/Canto do Lamim, Vargem Grande, Vargem Pequena, Ratones e Barra do Sambaqui. No sul da ilha, há Rio Tavares, Campeche, Tapera, Ribeirão da Ilha, Caieira da Barra do Sul e Costa de Dentro (ROSA, 2011).

A atividade da pecuária na Ilha de Santa Catarina está atrelada a diferentes usos, existem proprietários de dois ou três animais para os carros de boi, existe o gado familiar, normalmente para o consumo do leite, há a criação de gado de corte para a comercialização. Uma questão que chama a atenção na manutenção dos rebanhos em terrenos privados é o atributo que essa recebe da legislação. No Plano Diretor Participativo de Florianópolis, aprovado em janeiro de 2014, as áreas que anteriormente eram enquadradas como rurais receberam novas denominações: uma sob o título Área Residencial Rural e a outra, Área de Urbanização Especial. De acordo com a Lei Complemen$\operatorname{tar} n^{\circ} 482$ :

II - Área Residencial Rural (ARR) - onde coexistem usos urbanos e rurais de pequeno porte suportados por uma estrutura viária e fundiária rural, destinadas à produção agrícola e agropecuária familiar; e III - Área de Urbanização Especial (AUE) - grandes áreas urbanizáveis a partir de projeto amplo, que reserva setor predominante para preservação ambiental e adensa a área remanescente, criando novas centralidades caracterizadas pela mescla de funções e espaços humanizados (FLORIANÓPOLIS, 2015).

No entanto, a extinção das áreas rurais poderia pressupor que todos os proprietários de terrenos na ilha deveriam pagar o Imposto Predial e Territorial Urbano (IPTU). Como é possível verificar em dados coletados $^{7}$ por Alexandre Inkot, funcionário do Instituto Nacional de Colonização e Reforma Agrária (Incra), existem na ilha, atualmente, 1.106 imóveis cadastrados como rurais, totalizando uma área de 8.918,9689 hectares. Existe, portanto, um número considerável de propriedades que ainda pagam 
Imposto Territorial Rural (ITR). Para o Incra, o que define a característica da terra como rural são os usos feitos dela. Assim, criação de gado configura-se como uma atividade de uso rural, o que daria ao proprietário o direito de pagar o ITR em detrimento do IPTU.

Existem ainda, portanto, na ilha, algumas grandes áreas que no antigo plano diretor estariam enquadradas como áreas rurais; no novo plano, foram enquadradas como Áreas de Urbanização Especial, algo ainda bastante confuso na nova lei. Em uma delas, na qual pastam diariamente algumas cabeças de gado, os proprietários seguem pagando o imposto rural. Esse caso específico acabou virando processo judicial. Herdeiros de terras da família Ramos entraram na Justiça para requerer a manutenção do referido imposto. Nesse processo, em nome de Agro Pastoril C. Ramos Ltda., Dóris Ramos Gomes e Vilma Ramos Fonseca ajuizaram pedido de cancelamento de cobrança de IPTU pela prefeitura de Florianópolis. Na sentença final do processo, dado como ganho de causa para os outorgantes, foi utilizado como argumentação o fato de que o Imposto Territorial Rural pode também incidir sobre imóveis localizados em áreas urbanas, desde que mantenham o uso específico como consta no processo de 28 de maio de 2007, Autos 023.01.026834-3:

O ITR não incide somente sobre os imóveis localizados na zona rural do município, mas também sobre aqueles que, situados na área urbana, são comprovadamente utilizados em exploração extrativa, vegetal, pecuária ou agroindustrial (SANTA CATARINA, 2007).
Em meio à crescente especulação imobiliária que ocorre na ilha nos últimos quarenta anos, em áreas com grandes extensões, certamente, os valores cobrados pelo IPTU poderiam atingir cifras significativas. A presença do gado espalhado em parte dessas terras pode fazer jus ao argumento mencionado na sentença judicial; em terras em área urbana, com exploração pecuarista ou agroindustrial, o imposto que deve incidir sobre elas é o ITR.

$\mathrm{O}$ gado que se encontra espalhado em parte das terras referidas no processo indicado, somam aproximadamente 146 cabeças. Mas, esse número é dividido entre o caseiro, o dono da propriedade e alguns amigos, segundo informações do criador de gado e morador-caseiro da propriedade localizada no norte da ilha, Fabiano João Maria.

Fabiano $^{8}$ é nascido na ilha, sua família veio de Governador Celso Ramos, seus pais eram agricultores. Ele mora no bairro da Vargem Pequena desde 1996, quando ocupou o lugar do sogro, que anteriormente administrava a fazenda do ex-governador Celso Ramos. Atualmente, ele é funcionário da propriedade que pertence a Celso Ramos (neto do ex-governador). Sobre a propriedade do gado alocado naquelas terras, ele diz: "tamo hoje com 146 cabeça de gado, entre minha, patrão e de amigo, né, que a gente também ajuda o pessoal aí". Torna-se evidente que a criação de gado não é propriamente um negócio do proprietário do terreno. Animais pastando naquelas terras tem configurado um uso rural que pode servir a diferentes interesses em jogo, incluindo a questão dos impostos aqui referida e a reserva de áreas de larga extensão para o desenvolvimento 
futuro de grandes empreendimentos imobiliários. Complete-se: salvo pelos bois de uma forte taxação tributária. Fabiano também demonstrou conhecer os tributos que incidem sobre a terra que ele "cuida". Ele afirma: "o nosso terreno ainda tá como área rural, ele ainda tá como registrado no Incra, aí eu não sei até quanto tempo".

Sobre a relação entre pecuária e desmatamento, o criador de gado do norte da ilha fez questão de isentar a "culpa" dos animais. Ter animais não é prerrogativa somente dos criadores, faz parte das ruralidades presentes na ilha na atualidade. Bois que são utilizados como força de tração, para veículos ou nos engenhos de farinha, e vacas que fornecem o leite para o consumo familiar. Há a presença desses animais mesmo em espaços reduzidos, pois, muitas vezes, o proprietário nem tem campo próprio, usa terreno emprestado para o animal pastar.

O professor Nazareno Campos já fez estudos sobre as chamadas "terras de uso comunal", áreas que eram utilizadas por membros das comunidades para levar o gado para se alimentar ou para recolher lenha e madeira, ou ainda para a agricultura. Eram terras de uso comum e que, depois, acabaram sendo alvo de inúmeras apropriações indevidas. Essas terras não existem mais. Hoje, proprietários de gado usam terrenos de particulares emprestados. Manter esses animais e tê-los como animais de estimação também pode ser pensado a partir da emergência de novas sensibilidades em relação aos animais. Em evidência neste princípio de século XXI, novas sensibilidades em relação aos animais e também quanto ao meio ambiente promoveu o surgimento de ONGs e sociedades protetoras, que se tornam atuantes diante dos poderes constituídos para que leis visando à proteção ambiental, e de todas as espécies, sejam elaboradas. No que diz respeito aos animais de estimação, essas novas sensibilidades já foram articuladas em diferentes períodos da história.

Keith Thomas (2010), em seu livro $O$ homem e o mundo natural, argumenta que a ideia de condenar a crueldade em relação aos animais não é novidade da modernidade, era uma opinião já sustentada por autores clássicos, por escolásticos medievais, e reforçada no período moderno. As descobertas:

[...] revelavam não apenas que a terra não era o centro do mundo, mas que havia uma infinidade de mundos [...] ia se tornando mais difícil defender que a criação existisse para uso exclusivo e benéfico dos moradores humanos (2010, p. 236).

Astrônomos, botânicos e zoólogos fizeram descobertas que colocavam em pauta o antropocentrismo. No século XVIII, um culto a novas sensibilidades, em que:

[...] o modo de pensar pressupunha que o importante eram os sentimentos da criatura sofrente, não sua inteligência ou capacidade moral [...] os animais tinham sentimentos e tais sentimentos deviam ser respeitados (2010, p. 250-251).

O período atual abriu espaço para a emergência de diferentes movimentos em defesa dos direitos dos animais. De certa forma, essa nova consciência também interfere nas relações atuais entre os homens e mulheres e seus animais, sejam eles de pequeno ou grande porte. Com relação ao gado, famílias que mantém três, quatro ou seis animais 
narram seu apreço pelos bichos. Em matéria sobre esses animais na ilha, Edson Rosa destacou:

Aos 26 anos e a caminho da aposentadoria, Tiguera e Tigrão formam uma das juntas preferidas entre os 12 bois adultos que Fausto cria como amigos nos pastos da encosta do morro da Praia Comprida. É lá em cima que a família Andrade ainda planta a mandioca raspada para as farinhadas de inverno na Ilha. Matéria-prima carregada por Tufi e Torino, a parelha mais velha do rebanho de Fausto, com 30 anos, recolhida ao estábulo. Apegado aos bichos, o comerciante teme o momento da despedida dos animais de lidas e tenta minimizar o sofrimento com abrigo no estábulo e tratamento especial no cocho (ROSA, 2015, p. 5).

Essa relação entre animais e o homem é recriada constantemente. Dona Maria Joaquina dos Anjos, ${ }^{9}$ agricultora aposentada e moradora do Distrito do Rio Vermelho, em entrevista realizada na localidade, quando o assunto foi a caça que era praticada na ilha até quarenta anos atrás aproximadamente, ela logo afirmou: "[...] nunca comi caça não, eu tenho pena de matar os animais [...] deveria ter outra coisa pra gente se manter que não fosse o sacrifício da morte".

Essa sensibilidade em relação aos animais ficou evidente também quando o assunto foi o boi como força de trabalho no engenho de farinha. Sobre a utilização ou não de animais nos engenhos, duas questões ficaram bastante evidentes: a primeira diz respeito a essas novas sensibilidades com relação aos animais, e a outra diz respeito às questões legais e sanitárias do fabrico da farinha. $\mathrm{O}$ engenho movido a motor ou pela força motriz dos bois foi narrado de diferentes maneiras pelos entrevistados nesta pesquisa. O espaço foi apontado como limitador para o uso dos animais no engenho. Sérgio de Souza, o Marreba, proprietário de um engenho movido à máquina, no Canto do Lamim, afirmou que um dos fatores para não ter colocado a força motriz dos animais fora o espaço.

[...] ele ali é trabalhado a motor, tudo é motor de forno, de cevador, só motor, porque o espaço pro boi tem que ser maior, nós temos uma réplica lá, aquela replicazinha lá é com o boi, roda no engenho, então ele tem que ter um espaço suficiente pro boi rodar [...] para rodar com a canga.

O espaço, ou a falta dele, é um dos fatores para que o engenho seja movido pela energia elétrica. $\mathrm{O}$ engenho movido a boi fica agora na estante, em uma réplica que, com outros artefatos utilizados pelos familiares de Sérgio no seu cotidiano de trabalho na lavoura, hoje ajudam a compor esse cenário do novo engenho. $\mathrm{O}$ uso de engenhos movidos a máquinas não deixa de ser uma reelaboração das práticas do fabrico da farinha.

As justificativas para tal uso se referiam, em alguma medida, à aplicação das novas leis ambientais. Sérgio (Marreba), além da questão da falta de espaço, assim justifica a ausência dos bois:

[...] é a lei ambiental, agora ela tá sobre os animais rodando no engenho, são quinze minutos a cada animal rodando, então se quer ter um engenho grande, tem que ter no mínimo de três a quatro juntas de boi, são seis animais no caso, pra tá trocando [...] isso aí eu acho que é municipal.

O proprietário desse engenho no Lamim não soube identificar que legislação de- 
finiria o uso de animais no engenho. Ele acredita que seja uma "lei municipal". Em 2015, a Câmara Municipal de Florianópolis aprovou projeto de lei que proíbe o uso de carroças com tração animal nas ruas de Florianópolis. O Projeto de Lei 1.352/2014 proíbe o transporte de carga que se utilize de força animal, em que a carga tenha peso superior ao do animal (cabe destacar que os animais referidos são cavalo, mula ou burro), sendo que figuram como exceções locais privados, regiões periféricas e passeios turísticos.

Ainda que tenhamos uma legislação municipal que coíba o uso de transporte com força animal, esse projeto de lei recentemente aprovado pela Câmara de Florianópolis, não interfere, como afirmado anteriormente, em locais periféricos ou passeios turísticos. Nada é dito sobre o uso de bois nos carros de boi ou mesmo nos engenhos. Então, na prática, não existe atualmente uma legislação que limite o uso desses animais para esses fins. Assim, quando nas narrativas aparece uma preocupação em resguardar os animais de trabalho excessivo, está-se diante de uma mudança de atitude em relação aos animais na contemporaneidade. Essa mudança permite que sejam reelaboras as relações entre o homem e os animais.

$\mathrm{O}$ uso de máquinas nos engenhos em detrimento dos bois também é justificado pela referência às questões de ordem sanitária. Foi em Santa Catarina, em 1911, de acordo com Enilto de Oliveira Neubert (2013), que nasceu a indústria da fécula de mandioca. No Brasil, a Instrução Normativa Mapa $n^{0} 52 / 2011$ estabelece as diretrizes técnicas que regulamentam o fabrico de farinha de mandioca. Embora, nas entrevistas realiza- das para este trabalho, nenhum dono de engenho tenha afirmado sofrer qualquer tipo de pressão ou tentativa de coibir a produção por agentes da vigilância sanitária, a preocupação aparecia como justificativa para a retirada dos bois do engenho. O comerciante aposentado do Rio Vermelho, Hermínio dos Santos, o Nem, possui engenho movido a boi, no entanto, manifestou preocupação com a questão da "vigilância":

Ah tem isso é, porque tem vizinho, porque tem vizinho, porque você sabe, sempre os vizinho são as pessoas que a gente preci$\mathrm{sa}$, mas às vezes ele gosta de cachorro $\mathrm{e}$ não gosta de boi [...] quando eu tinha vaca de leite, tive problema, a vigilância veio diversas vezes aqui que eu não podia ter gado aqui.

Essa preocupação faz sentido na medida em que os processos de urbanização trazem também novas legislações e determinações para o uso do solo, a criação de animais, a produção, venda e consumo de alimentos. Essas tensões entre o que é permitido ou deixa de ser com a urbanização não é recorrente só nas questões ambientais e sanitárias, é evidente também quando o assunto são as disputas simbólicas em torno da cidade.

\section{Consideraçoes finais}

O município de Florianópolis, sediado em grande parte em uma ilha, teve um processo peculiar de urbanização. O crescimento, nas décadas de 1970 e 1980, impulsionado pela indústria da construção civil, pela implementação de órgãos estatais e pela indústria do turismo não foi capaz de apagar as marcas de um passado rural. 
O processo de urbanização levou a expansão da área central na direção dos antigos núcleos agrícolas e pesqueiros, transformando seus espaços e promovendo alterações na dinâmica econômica e cultural de seus moradores. Na década de 1980, embalada pelo crescimento urbano e pela ocupação desordenada dos antigos núcleos do interior da ilha, houve a elaboração de um novo Plano Diretor dos Balneários e a organização de uma legislação que construiu parâmetros para novos usos da terra e do meio ambiente. Juntamente com a legislação ambiental em nível estadual, o Código Estadual do Meio Ambiente e a legislação federal de defesa às espécies ameaçadas de extinção formam novos elementos que estiveram presentes nas relações dos moradores dessas regiões com o meio que os circunda. Em janeiro de 2014, foi aprovado o novo plano diretor para o município de Florianópolis, o Plano Diretor Participativo de Florianópolis.

Entre o Plano Diretor dos Balneários e o Plano Diretor Participativo, o último atualmente vigente no município, as áreas outrora definidas como rurais foram extintas. Desde a promulgação desse último plano diretor, de 2014, não existem mais áreas rurais na ilha. O que persiste são áreas em que os usos rurais são permitidos. Portanto, dentro de áreas ditas urbanas, ou em expansão urbana, práticas de agricultura e pecuária estão presentes.

No que diz respeito às práticas agrícolas, além da redução dos espaços devido ao processo de expansão urbana, a proibição das queimadas e a regulamentação das espécies enquadradas como ameaçadas de extinção constituem-se como novos elementos na vida de famílias que ainda tem na terra pedaços de sua vivência cotidiana. Como já foi mencionado, esses novos elementos não levaram à extinção do rural na ilha, mas, sim, produziram novas ruralidades, transformadas e contemporâneas. Nessas, o uso da terra é reestruturado dentro de novas perspectivas, é ressignificado. Em grande parte dos casos, a terra não é mais o espaço de sobrevivência, mas seu cultivo é a manutenção de um sentimento de pertencimento a determinadas práticas culturais, a um passado que tinha na terra sua forma de existência.

A prática da pecuária, a criação de animais e o uso de animais nos engenhos também sofreram alterações nesse processo. Longe de representar uma mudança homogênea, o uso dos animais na ilha representa atualmente um universo complexo de significados: dos criadores de gado para uso nos engenhos ainda movidos à tração animal àqueles que têm na manutenção de cabeças de gado em seus terrenos elementos para justificar o pagamento do Imposto Territorial Rural em detrimento do Imposto Predial e Territorial Urbano.

Muitos agricultores entrevistados para esta pesquisa mantêm seus antigos cultivos em terrenos hoje enquadrados como área de preservação permanente. É visível em muitos de seus terrenos a mata em diferentes estágios de regeneração. Atualmente, o maior risco para o meio ambiente insular é decorrente da crescente especulação imobiliária, que tem promovido parcelamento do solo, ancorado pela legislação ou não. Esses, ao contrário das antigas áreas agrícolas, que se regeneram com o tempo, ao cobrir a terra com tapetes de cimento, avançar sobre áreas 
de restinga (como muitos empreendimentos turísticos prontos e em construção na ilha), tornam os danos irreversíveis.

A cidade de Florianópolis é atualmente alvo de gigantescos investimentos, oriundos de capital nacional e internacional. O desejo de habitar uma cidade em que as pessoas possam conviver de forma mais equilibrada com o ambiente tem motivado a organização de várias parcelas da sociedade civil em movimentos contra empreendimentos imobiliários que colocam em risco o meio ambiente e a própria vida na cidade.

É parte desses novos movimentos da cidade, que buscam uma relação mais equilibrada entre sociedade e ambiente, a estruturação na ilha da primeira rede de agricultura urbana. Organizada pelo Centro de Estudos e Promoção da Agricultura de Grupo, essa iniciativa é parte de um movimento que percebe a cidade além das prerrogativas do consumo imediatista preconizado pela indústria do turismo e da construção civil. Nesse sentido, os usos da terra voltados para a agricultura e a produção de alimentos voltam a ser valorizados como parte de uma sociedade em que campo e cidade podem fazer parte de uma mesma realidade, não como polos opostos, mas como partes intercambiáveis.

\section{Abstract}

The city of Florianopolis has most of its territory located on an island, of 436.5 square kilometers, only 12.1 square kilometers from the mainland. The insular territorial configuration carries with it limits on urban growth. By law $42 \%$ of islet territory falls as APP (Permanent Preservation Area). This island was until the mid-twentieth century space farming and pastoral, being deeply transformed from the 70s of the century due to urban expansion process towards the old centers of fishing and agriculture. The opening of access roads accompanied by a political project capital city's transformation wrought significant changes in lifestyles of the populations living in the ancient core located around the island. The process of urban expansion, accompanied by the decline in agricultural and pastoral activities, did not lead to their elimination, but changed their practices and produced new relationships between men and women and the environment. From the 80 s of XX century, a new master plan defined the conservation areas created parameters for land use and urban sprawl. This article aims to analyze transformations in agriculture and livestock practices created in Florianopolis from the urbanization process and the development of environmental legislation that focuses on land use. These have been guiding elements for the emergence of new ruralities, contemporary ruralities.

Keywords: Rurality. Agriculture. Environment.

\section{Resumen}

La ciudad de Florianópolis tiene la mayor parte de su territorio se encuentra en una isla, de 436,5 kilómetros cuadrados, sólo 12,1 kilómetros cuadrados formar el continente. La configuración territorial insular lleva consigo limita el 
crecimiento urbano. Por ley el $42 \%$ del territorio de los islotes cae en forma de APP (Área de Preservación Permanente). Esta isla fue hasta mediados del XX la agricultura espacio de siglo y pastoral, siendo profundamente transformada a partir de los años 70 del siglo debido al proceso de expansión urbana hacia los antiguos centros de la pesca y la agricultura. La apertura de caminos de acceso acompañados por transformación de una ciudad capital el proyecto político de forjado cambios significativos en el estilo de vida de las poblaciones que viven en la antigua central situada alrededor de la isla. El proceso de expansión urbana, acompañada de la disminución de las actividades agrícolas y de pastoreo, no dio lugar a su eliminación, pero cambió sus prácticas y produjo nuevas relaciones entre hombres y mujeres y el medio ambiente. Desde los años 80 del siglo $X X$, un nuevo plan maestro define las áreas de conservación parámetros creados para el uso del suelo y la expansión urbana. Este artículo tiene como objetivo analizar las transformaciones en la agricultura y la ganadería prácticas creadas en Florianópolis desde el proceso de urbanización y el desarrollo de la legislación ambiental que se centra en el uso del suelo. Estos han estado guiando elementos para el surgimiento de nuevas ruralidades, ruralidades contemporáneos.

Palabras clave: La ruralidad. La agricultura. El medio ambiente.

\section{Notas}

1 Entrevista concedida à autora em 5 de junho de 2015.

2 Entrevista concedida à autora em 12 de abril de 2015.

3 Entrevista concedida à autora em 12 de abril de 2015.

4 Entrevista concedida à autora em 21 de janeiro de 2015.

5 Entrevista concedida à autora em 21 de janeiro de 2015.

6 Entrevista concedida à autora em 5 de junho de 2015.

7 Os dados foram elaborados com base no cadastro do Sistema Nacional de Cadastro Rural (SNCR). Disponível em: < https://sncr.serpro.gov.br>. O funcionário Alexandre Inkot acessou esses dados em: 7 mar. 2014.

8 Entrevista concedida à autora em 23 de março de 2015.

$9 \quad$ Entrevista concedida à autora em 5 de junho de 2015.

\section{Referências}

BRASIL. Ministério do Meio Ambiente. Instrução Normativa $\mathrm{n}^{\circ}$ 6, de 23 de setembro de 2008. Disponível em: <http://www.mma.gov.br/estruturas/179/_arquivos/179_05122008033615. pdf>. Acesso em: 20 jul. 2015.

CARNEIRO, Maria José T.; PEREIRA, Jorge Luiz de Goes. Tecendo novas estratégias: confecções em domicílios rurais em Nova Friburgo. In: CARNEIRO, Maria José T. (Org.). Ruralidades contemporâneas: modos de viver e pensar o rural na sociedade brasileira. Rio de Janeiro: Mauad X; Faperj, 2012. p. 101-152.

CARNEIRO, Maria José; TEIXEIRA, Vanessa Lopes. De terra de plantação à terra de lazer. In: CARNEIRO, Maria José (Org.). Ruralidades contemporâneas: modos de viver e pensar o rural na sociedade brasileira. Rio de Janeiro: Mauad X; Faperj, 2012. p. 67-100.

CESCO, Susana. A questão florestal na história da Ilha de Santa Catarina. Anos 90, Porto Alegre, v. 18, n. 33, p. 191-215, jul. 2011.

FERREIRA, Gilmara de Campos. Morros da lavoura: a vida agrícola na Freguesia de Nossa Senhora da Conceição da Lagoa (1875-1900). 2010. Monografia (Graduação em História) - 
Universidade Federal de Santa Catarina, Florianópolis, 2010.

FLORIANÓPOLIS. Lei Complementar $\mathrm{n}^{\circ} 482$, de 17 de janeiro de 2015. Florianópolis, SC, 2014. Disponível em: <http://www.pmf. sc.gov.br/sites/planodiretor $/ \mathrm{cms}=$ plano $+\mathrm{d}$ iretor+de+florianopolis>. Acesso em: 20 jul. 2015.

GUERINI, Eduardo. Metropolização e impactos socioambientais em Florianópolis, (1986-1996). 2000. Dissertação (Mestrado em Sociologia Política) - Universidade Federal de Santa Catarina, Florianópolis, 2000.

LIMA, Débora. Ilha de Santa Catarina: desenvolvimento urbano e meio ambiente. Florianópolis: Letras Contemporâneas, 2007.

NEUBERT, Enilto de Oliveira. Santa Catarina: o berço da industrialização da mandioca. Revista Agropecuária Catarinense, Florianópolis, v. 26, n. 1, mar. 2013.

REIS, Almir Francisco. Ilha de Santa Catarina: permanências e transformações. Florianópolis: UFSC, 2012.

Preservação ambiental no contexto urbano: cidade e natureza na Ilha de Santa Catarina. Revista Brasileira de Estudos Urbanos e Regionais, Recife, v. 12, n. 1, maio 2010.

ROSA, Edson. Criação de bovinos é alternativa econômica. 2011. Disponível em: <http:// www.ndonline.com.br/florianopolis / noticias/19291-criacao-de-bovinos-e-alternativa-economica-de-lazer-e-subsistencia-no-interior-de-florianopolis.html>. Acesso em: 25 jul. 2015.

ROSA, Edson. Boi na farra é boi de lida e cantoria. Jornal Notícias do Dia, Florianópolis, p. 5-8, 4-5 abr. 2015.

RUA, João. Urbanidades no rural: o devir de novas territorialidades. Campo-território: Revista de Geografia Agrária, Uberlândia, v. 1, n. 1, p. 82-106, fev. 2006.
SANTA CATARINA. Lei $\mathrm{n}^{\circ}$ 14.675, de 13 de abril de 2009. Institui o Código Estadual do Meio Ambiente. Florianópolis, 2009. Disponível em: <http://www.institutohorus.org.br/ download/marcos_legais/Lei\%2014.675\%20 Codigo_ambiental_SC.pdf>. Acesso em: 20 jul. 2015.

Poder Judiciário. Visto aos autos 023.01.026834-3. Apelante: Agro Pastoril C. Ramos Ltda, Doris Ramos Gomes e Vilma Ramos Fonseca. Apelado: Prefeitura Municipal de Florianópolis. Relator: Juiz Hélio do Valle Pereira. Florianópolis, 28 de maio de 2007.

THOMAS, Keith. O homem e o mundo natural: mudanças de atitude em relação às plantas e aos animais (1500-1800). São Paulo: Companhia das letras, 2010. 